\title{
Why is Zika virus so rarely detected during outbreaks and how can detection be improved?
}

\author{
Diawo Diallo* and Mawlouth Diallo
}

\begin{abstract}
Objective: Even during outbreaks, detection of Zika virus (ZIKV; genus Flavivirus, family Flaviviridae) in its mosquito vectors is surprisingly uncommon. Here we explore the reason for this apparent paradox and suggest strategies for improving the efficacy of ZIKV detection.

Results: There are several likely explanations for the rarity of ZIKV detection in field-collected mosquitoes during outbreaks, including the lag between the period when people are clinically ill and the initiation of entomological investigations, the prompt spraying of houses of identified cases, the difficulty of identifying some of the households of ZIKV infected cases, and the low efficiency of the sampling methods currently available. Thus, timely entomological investigation of suspected cases before the intervention of the vector control squad would enhance ZIKV detection from mosquitoes. For this to happen, administrative, financial and logistical issues must be solved before the beginning of outbreaks, and routine entomological surveillance must be conducted in foci of ZIKV amplification. Improving ZIKV detection during outbreaks is of paramount importance because identification of the mosquito species and population involved as vector in a given outbreak is a key element to a comprehensive and effective vector control strategy.
\end{abstract}

Keywords: Zika, Arbovirus, Outbreaks, vectors, Field-collected mosquitoes

\section{Introduction}

Mosquito-borne Zika virus (ZIKV; genus Flavivirus, family Flaviviridae) has spread globally in recent years. Until 2006, this arbovirus was only known in Africa and Asia and considered of minor interest [1,2]. During this period, transmission occurred mainly in a sylvatic cycle involving arboreal Aedes and non-human primates [3]. Only a few human cases have been described in this sylvatic cycle with mild symptoms including rash, joint pain and conjunctivitis [2]. The first major outbreak of ZIKV was observed on Yap Island in 2007 [1], thereafter outbreaks occurred on several islands in the Pacific including French Polynesia in 2013 and 2014 [4, 5]. Nevertheless, this virus really attracted world attention when it arrived in South America in 2015. Indeed, in

*Correspondence: Diawo.Diallo@pasteur.sn

Unité d'Entomologie Médicale, Institut Pasteur de Dakar, 36 Avenue Pasteur, BP 220, Dakar, Senegal
Brazil alone, more than 1,300,000 suspected cases were recorded including cases with neurological complications like Guillain-Barré syndrome and more than 3000 cases of microcephaly in newborns of women infected during pregnancy $[6,7]$. To date, over 84 countries and territories have experienced local mosquito-borne transmission of ZIKV, and imported cases were recorded in many other countries in Europe and Americas [8]. Although cases of sexual and congenital transmission of ZIKV have been reported, ZIKV is likely transmitted between humans mainly by the mosquito Ae. aegypti [9] and to a lesser extent by Ae. albopictus [10]. Indeed, only these two species have been found naturally infected with ZIKV during outbreaks [10-17]. In addition, they are the only vectors with ecological opportunity to maintain outbreaks that have also been shown to transmit the virus in laboratory assays [18-20]. Yet despite the increase in the number, frequency and severity of ZIKV outbreaks, the virus has rarely been detected in mosquitoes in the 
vicinity of these outbreaks. Indeed, ZIKV was detected from mosquitoes collected during outbreaks only in the following four countries: Gabon (from Ae. albopictus in 2007 [10]), Mexico (from Ae. aegypti in 2015-16 [11, 16]), Brazil (from Ae. albopictus adults in 2016 [17], from Ae. aegypti adults in 2015-16 [12, 15] and Ae. albopictus eggs in 2015 [14]), and Singapore (from Ae. aegypti and Ae. albopictus in 2016 [13]). Several entomological investigations following outbreaks in Yap Island [21], French Polynesia, Brazil [22], American countries, Cabo Verde, Guinea Bissau (Diallo et al. unpublished data) in which several mosquito species were collected from the field and tested by real-time RT-PCR and/or virus isolation attempts failed to detect ZIKV. This paucity of detection is surprising for a primarily vector-borne disease. The reasons for low detection rates must be identified and addressed, because the identification of the mosquito species involved as vectors in a given outbreak is a key element to a comprehensive and consolidated action plan for vector control.

The aim of this paper is to present some probable explanations of the rarity of ZIKV detection from mosquito vectors collected in the vicinity of ZIKV outbreaks.

\section{Main text}

The overall objective of the entomological investigation of an outbreak is to collect data on mosquitoes (including their identity, abundance, behavior and infection status) in and around households of infected patients as well as the path of their movements during the period of host viremia. These data are used to inform decisions on an effective vector control strategy.

Thus, failure to detect ZIKV during outbreaks significantly hinders ZIKV control. There are at least four explanations for the lack of ZIKV detection in field-collected mosquitoes during outbreaks:

\section{Delay between identifying illness in people and conducting field investigations}

In the few ZIKV outbreaks investigated by entomologists, investigations were sometimes conducted several months after the detection of the outbreak. In the first large ZIKV outbreak in Yap in 2007, there was a delay of about 3 months between the beginning of the outbreak in April and the entomological investigation in July [21]. In the recent ZIKV outbreaks observed in Africa, this delay was 7 months in Cabo Verde (first human cases detected in October 2015 and the beginning of the entomological investigation at the end of March 2016) and 3 months in Guinea Bissau (first human cases detected in may 2016 and the entomological investigation done in August 2016) (Diallo et al. unpublished data). If we take into account the short lifespan of female mosquitoes including Ae. aegypti, investigations are generally made after turnover of the population responsible for the outbreak. Moreover, some investigations are conducted much later, when mosquito populations are at their lowest level or have completely disappeared as a result of the installation of seasonal changes in weather. ZIKV was detected from field-collected mosquitoes during outbreaks when entomological investigations were made in and around households of clinically ill patients, indicating that the transmission was still ongoing [10-13]. For the first detection of the virus in Brazil, mosquitoes were collected during the same week as clinical diagnostic of the patients [12]. All others detections from field-collected mosquitoes were from samples collected during routine entomological surveillance of arboviruses $[3,9$, $16,23,24]$.

Delay in entomological investigations in response to outbreaks is primarily attributable to delays in diagnosis and reporting of cases due to lack of knowledge of the disease by physicians, high proportion of asymptomatic cases, and the lack of rapid diagnostics for flavivirus infections [25]. Other reasons for delays include lack of experts in medical entomology $[26,27]$ as well as administrative and financial barriers. Medical entomologists are mainly trained in Masters and Ph.D. programs in relatively few universities and research institutions around the world. Only a small proportion of these entomologists have specific expertise in arboviruses. Thus, there is an urgent need to train and employ individuals with the skills to conduct entomological investigations in response to arbovirus outbreaks in all countries within the sphere of ZIKV transmission risk. Administrative issues that delay outbreak investigations include inadequate training of management staff, lack of coordination, lack of procedures or excessively complex procedures for decision making, data collection and transmission, reluctance to share data at the national and international level, and the low priority given to unknown, rare and unplanned events. Little, and in some cases no, national funding is dedicated to outbreak investigations in many countries. Emergency funding may be available via international agencies like World Health Organization but this must be requested by national authorities and the time required to process and consider such requests further delays the investigation.

\section{Difficulty in identifying Zika-infected households}

The second explanation for failure to detect ZIKV in mosquitoes is the difficulty of identifying the exact households of ZIKV infected cases. Sampling mosquitoes within ZIKV case households increases the probability of detecting infected mosquitoes because Ae. aegypti females are mainly endophilic with very limited spatial 
dispersal, often spending their entire lives in the room where they emerged [28]. An entomological investigation in randomly selected houses failed to detect ZIKV in mosquito in Yap [21], while positive pools were detected when mosquito were collected in and around clinically ill patient households [10-12]. During outbreak investigations, households of Zika patients are identified via the addresses or phone numbers found in medical registers or patient identification forms sent by physicians to the laboratory along with samples for diagnosis. However, only around $20 \%$ of these ZIKV infected people are symptomatic [2], and an even smaller fraction seek medical care and thus may be identified and investigated through this system. Moreover, in many cases basic location information (exact address and phone number) are not reported in medical documents. Thus, it is impossible to identify and investigate the majority of households in which a ZIKV-infected individual lives. Further, it is not certain that a given patient was infected in his/ her own household because infections could have been contracted in other neighborhoods or villages during the course of normal movements. To alleviate this problem, medical personnel must be instructed to clearly record the address, phone number and travel history in each patient identification form.

\section{Inefficient sampling methods}

The third explanation of the scarcity of ZIKV detection in field collected mosquitoes is the low efficiency of the sampling methods currently available and commonly used for collecting populations of Aedes vectors [29, 30]. The collection of host seeking females by human landing catch is still probably the most effective method for $A e$. aegypti and for sylvatic ZIKV vectors, but this method raises some ethical concerns. Humans used as collectors are exposed to the bite of potentially infective mosquitoes especially during epidemics [31]. People who have already been in contact with the virus (IgG or IgM positives) could be used as mosquito collectors because they are protected against ZIKV, but they are still exposed to other arboviruses and pathogens transmitted by mosquitoes. Other methods for collection include CDC light traps, backpack aspirators, resting site collections, BGsentinel traps and various gravid traps; each comes with specific limitations. Ae. aegypti is not very attracted to the CDC light traps. The weight of the backpack aspirator makes it difficult to use and its performance depends on the competence and motivation of the operator [32]. It is extremely difficult to identify Aedes resting sites, making it difficult to collect an adequate number of mosquitoes. BG-sentinel traps have been shown to effectively collect Ae. aegypti [33] and Ae. albopictus [34].
However, data about their efficiency for sylvatic vector species and during ZIKV outbreak investigations are lacking.

ZIKV and many other flaviviruses infect mosquitoes at low rates, thus, to detect these viruses is necessary to collect a very large number of mosquitoes. Using statistical models, Gu et al. [35] have described methods to estimate the probability of arbovirus detection in mosquito populations. They showed that detection of low levels of mosquito infections requires large samples (greater than 1600 individuals) for a high (80\%) probability of detection. They also indicated that grouping samples over different sampling sites and times is inappropriate for detection of mosquito infection due to focal transmission of arboviruses. Adult ZIKV vectors have been collected during outbreaks using light traps, vacuum aspiration and gravid traps in Yap [21], aspiration in Brazil and Mexico [11, 12], gravid traps in Singapore [13] and human landing catch in Gabon [10]. ZIKV has been detected from adult mosquitoes collected during outbreaks by aspiration in Brazil and Mexico [11, 12], gravid traps in Singapore [13] and human landing catch in Gabon [10]. The virus was also detected from adult mosquitoes collected as eggs during the ZIKV outbreak in Brazil in 2015 [14]. Because ZIKV, chikungunya and dengue are transmitted mainly by Ae. aegypti, these limitations of sampling apply to all three viruses. In contrast, West Nile virus is transmitted by mainly ornithophilic and zoophilic mosquitoes. Culex are efficiently collected by a variety of trapping tools including dry-ice supplemented CDC light traps and CDC gravid traps [36, 37]. Development of new sampling tools that most closely mimic human landing catch is still needed for entomological investigation for ZIKV outbreaks. The utility of adding a heat source and human body shaped support to the BG sentinel trap should be explored.

\section{The prompt spraying of houses once cases are identified}

The last explanation for the common failure to detect ZIKV in mosquitoes is that vector control is undertaken quickly during some outbreaks. As soon as a suspected case is detected, the vector control squad goes to spray within and around his/her household. These prompt reactions probably eliminate the infected population around identified human cases. Vector control squads should be trained for the basic skills needed for entomological investigation including collecting and handling mosquito samples for morphological identification and virological testing. This way surveillance can be implemented without delaying necessary public health interventions. 


\section{Limitations}

The main limitation of this discussion is the lack of published data on the entomological investigations of ZIKV outbreaks, especially when the virus was not detected in mosquitoes. Thus, proposed explanations described here were mainly drawn from our own experiences in the investigation of arbovirus outbreaks (including ZIKV) as experts that have been deployed by international health organizations in several African countries. To our knowledge this is the first comprehensive consideration of the barriers that curtail the efficacy of mosquito surveillance during ZIKV outbreaks. Some of these factors are universal (i.e. the low efficiency of CDC light traps for Ae. aegypti) whereas others will apply to only a subset of countries within the range of ZIKV transmission (i.e. specific administrative barriers). Moreover, we recognize that the solution to some of these barriers are political or administrative and that some intersect with protections of personal privacy issues and thus will not be easily implemented in all ZIKV affected countries.

\section{Abbreviations}

ZIKV: Zika virus; RT-PCR: reverse transcriptase-polymerase chain reaction.

\section{Authors' contributions}

DD drafted the manuscript, and MD contributed in writing and revised the manuscript critically for important intellectual content. Both authors read and approved the final manuscript.

\section{Acknowledgements}

Not applicable.

\section{Competing interests}

The authors declare that they have no competing interests.

\section{Availability of data and materials}

Not applicable.

\section{Consent for publication}

Not applicable.

\section{Ethics approval and consent to participate}

Not applicable.

\section{Funding}

Not applicable.

\section{Publisher's Note}

Springer Nature remains neutral with regard to jurisdictional claims in published maps and institutional affiliations.

Received: 5 July 2017 Accepted: 23 October 2017

Published online: 30 October 2017

\section{References}

1. Duffy MR, Chen TH, HancockWT, Powers AM, Kool JL, Lanciotti RS, Pretrick M, Marfel M, Holzbauer S, Dubray C, et al. Zika virus outbreak on Yap Island, Federated States of Micronesia. NEngl J Med. 2009;360(24):2536-43.
2. Musso D, Gubler DJ. Zika virus. Clin Microbiol Rev. 2016;29(3):487-524

3. Diallo D, Sall AA, Diagne CT, Faye O, Faye O, Ba Y, Hanley KA, Buenemann M, Weaver SC, Diallo M. Zika virus emergence in mosquitoes in southeastern Senegal, 2011. PLoS ONE. 2014;9(10):e109442.

4. Cao-Lormeau VM, Roche C, Teissier A, Robin E, Berry AL, Mallet HP, Sall AA, Musso D. Zika virus, French polynesia, South pacific, 2013. Emerg Infect Dis. 2014;20(6):1085-6.

5. Musso D, Nilles EJ, Cao-Lormeau VM. Rapid spread of emerging Zika virus in the Pacific area. Clin Microbiol Infect. 2014;20(10):0595-6.

6. Bogoch II, Brady OJ, Kraemer MU, German M, Creatore MI, Kulkarni MA, Brownstein JS, Mekaru SR, Hay SI, Groot E, et al. Anticipating the international spread of Zika virus from Brazil. Lancet. 2016;387(10016):335-6.

7. Schuler-Faccini L, Ribeiro EM, Feitosa IM, Horovitz DD, Cavalcanti DP, Pessoa A, Doriqui MJ, Neri Jl, Neto JM, Wanderley HY, et al. Possible association between Zika virus infection and microcephaly-Brazil, 2015. MMWR. 2016;65(3):59-62.

8. World Health Organization. Zika situation report. http://apps.who.int/iris/ bitstream/10665/254714/1/zikasitrep10Mar17-eng.pdf?ua=1. Accessed 10 Mar 2017.

9. Marchette NJ, Garcia R, Rudnick A. Isolation of Zika virus from Aedes aegypti mosquitoes in Malaysia. Am J Trop Med Hyg. 1969;18(3):411-5.

10. Grard G, Caron M, Mombo IM, Nkoghe D, Mboui Ondo S, Jiolle D, Fontenille D, Paupy C, Leroy EM. Zika virus in Gabon (Central Africa)-2007: a new threat from Aedes albopictus? PLoS Negl Trop Dis. 2014;8(2):e2681.

11. Guerbois M, Fernandez-Salas I, Azar SR, Danis-Lozano R, Alpuche-Aranda CM, Leal G, Garcia-Malo IR, Diaz-Gonzalez EE, Casas-Martinez M, Rossi SL, et al. Outbreak of Zika Virus Infection, Chiapas State, Mexico, 2015, and first confirmed transmission by Aedes aegypti mosquitoes in the Americas. J Infect Dis. 2016;214(9):1349-56.

12. Ferreira-de-Brito A, Ribeiro IP, Miranda RM, Fernandes RS, Campos SS, Silva KA, Castro MG, Bonaldo MC, Brasil P, Lourenco-de-Oliveira R. First detection of natural infection of Aedes aegypti with Zika virus in Brazil and throughout South America. Mem Inst Oswaldo Cruz. 2016;111(10):655-8.

13. Singapore Zika Study. G: outbreak of Zika virus infection in Singapore: an epidemiological, entomological, virological, and clinical analysis. Lancet Infect Dis. 2017;17(8):813-21.

14. Smartt CT, Stenn TMS, Chen TY, Teixeira MG, Queiroz EP, Souza Dos Santos L, Queiroz GAN, Ribeiro Souza K, Kalabric Silva L, Shin D et al. Evidence of Zika Virus RNA Fragments in Aedes albopictus (Diptera: Culicidae) field-collected eggs from Camacari, Bahia, Brazil. J Med Entomol. 2017:54(4):1085-87

15. Ayllon T, Campos RM, Brasil P, Morone FC, Camara DCP, Meira GLS, Tannich E, Yamamoto KA, Carvalho MS, Pedro RS, et al. Early evidence for Zika virus circulation among Aedes aegypti mosquitoes, Rio de Janeiro, Brazil. Emerg Infect Dis. 2017;23(8):1411-2.

16. Diaz-Quinonez JA, Lopez-Martinez I, Torres-Longoria B, Vazquez-Pichardo M, Cruz-Ramirez E, Ramirez-Gonzalez JE, Ruiz-Matus C, Kuri-Morales P. Evidence of the presence of the Zika virus in Mexico since early 2015. Virus Genes. 2016;52(6):855-7.

17. Pan American Health Organization/World Health Organization. Zika virus detection in Aedes albopictus in Mexico. Zika epidemiological update. Washington (DC): PAHO/WHO; 2016. http://www.paho.org/hq/index. php?option $=$ com_docman\&task=doc_view\&ltemid $=270 \&$ gid $=34243 \& \mathrm{l}$ ang=en. Accessed 21 Apr 2016.

18. Chouin-Carneiro T, Vega-Rua A, Vazeille M, Yebakima A, Girod R, Goindin D, Dupont-Rouzeyrol M, Lourenco-de-Oliveira R, Failloux AB. Differential susceptibilities of Aedes aegypti and Aedes albopictus from the Americas to Zika virus. PLoS Negl Trop Dis. 2016;10(3):e0004543.

19. Li CX, Guo XX, Deng YQ, Xing D, Sun AJ, Liu QM, Wu Q, Dong YD, Zhang YM, Zhang HD, et al. Vector competence and transovarial transmission of two Aedes aegypti strains to Zika virus. Emerg Microb Infect. 2017;6(4):e23.

20. Richard V, Paoaafaite T, Cao-Lormeau VM. Vector Competence of French Polynesian Aedes aegypti and Aedes polynesiensis for Zika virus. PLoS Negl Trop Dis. 2016;10(9):e0005024.

21. Ledermann JP, Guillaumot L, Yug L, Saweyog SC, Tided M, Machieng P, Pretrick M, Marfel M, Griggs A, Bel M, et al. Aedes hensilli as a potential vector of Chikungunya and Zika viruses. PLoS Negl Trop Dis. 2014;8(10):e3188.

22. Costa-da-Silva AL, loshino RS, Petersen V, Lima AF, Cunha MDP, Wiley MR, Ladner JT, Prieto K, Palacios G, Costa DD, et al. First report of naturally 
infected Aedes aegypti with chikungunya virus genotype ECSA in the Americas. PLoS Negl Trop Dis. 2017;1 1(6):e0005630.

23. Haddow AJ, Williams MC, Woodall JP, Simpson DI, Goma LK. Twelve isolations of Zika virus from Aedes (Stegomyia) Africanus (Theobald) taken in and above a Uganda Forest. Bull World Health Organ. 1964;31:57-69.

24. Cornet M, Robin Y, Chateau R, Heme G, Adam C, Valade M. Isolement d'arbovirus au Senegal oriental a partir de moustiques (1972-1977) et note sur l'epidemiologie des virus transmis par les Aedes, en particulier du virus amaril. Cahier ORSTOM Serie Entomol Med Parasitol. 1979;17:149-63.

25. Shragai T, Tesla B, Murdock C, Harrington LC. Zika and chikungunya: mosquito-borne viruses in a changing world. Ann NY Acad Sci. 2017;1399(1):61-77

26. Cuisance D, Antoine Rioux J. Current status of medical and veterinary entomology in France: endangered discipline or promising science? Comp Immunol Microbiol Infect Dis. 2004;27(5):377-92.

27. Almeida APG, Fouque F, Launois P, Sousa CA, Silveira H. From the laboratory to the field: updating capacity building in medical entomology. Trends Parasitol. 2017;33(9):664-8

28. Harrington LC, Scott TW, Lerdthusnee K, Coleman RC, Costero A, Clark GG, Jones JJ, Kitthawee S, Kittayapong P, Sithiprasasna R, et al. Dispersal of the dengue vector Aedes aegypti within and between rural communities. Am J Trop Med Hyg. 2005;72(2):209-20.

29. Diallo M, Dia I, Diallo D, Diagne CT, Ba Y, Yactayo S. Perspectives and challenges in entomological risk assessment and vector control of chikungunya. J Infect Dis. 2016;214(suppl 5):S459-65.
30. Sivagnaname N, Gunasekaran K. Need for an efficient adult trap for the surveillance of dengue vectors. Indian J Med Res. 2012;136(5):739-49.

31. Williams CR, Long SA, Russell RC, Ritchie SA. Field efficacy of the BGsentinel compared with CDC Backpack Aspirators and $\mathrm{CO}_{2}$-baited EVS traps for collection of adult Aedes aegypti in Cairns, Queensland, Australia. J Am Mosq Control Assoc. 2006;22(2):296-300.

32. Service MW. Mosquito ecology field sampling methods. Netherlands: Springer; 1993.

33. Harwood JF, Arimoto H, Nunn P, Richardson AG, Obenauer PJ. Assessing carbon dioxide and synthetic lure-baited traps for dengue and chikungunya vector surveillance (3). J Am Mosq Control Assoc. 2015;31(3):242-7.

34. Farajollahi A, Kesavaraju B, Price DC, Williams GM, Healy SP, Gaugler R, Nelder MP. Field efficacy of BG-Sentinel and industry-standard traps for Aedes albopictus (Diptera: Culicidae) and West Nile virus surveillance. J Med Entomol. 2009;46(4):919-25.

35. Gu W, Novak RJ. Short report: detection probability of arbovirus infection in mosquito populations. Am J Trop Med Hyg. 2004;71(5):636-8.

36. Godsey MS Jr, Burkhalter K, Young G, Delorey M, Smith K, Townsend J, Levy C, Mutebi JP. Entomologic investigations during an outbreak of West Nile virus disease in Maricopa County, Arizona, 2010. Am J Trop Med Hyg. 2012;87(6):1125-31.

37. Reisen W, Lothrop H, Chiles R, Madon M, Cossen C, Woods L, Husted S, Kramer V, Edman J. West Nile virus in California. Emerg Infect Dis. 2004;10(8):1369-78

\section{Submit your next manuscript to BioMed Central and we will help you at every step:}

- We accept pre-submission inquiries

- Our selector tool helps you to find the most relevant journal

- We provide round the clock customer support

- Convenient online submission

- Thorough peer review

- Inclusion in PubMed and all major indexing services

- Maximum visibility for your research

Submit your manuscript at www.biomedcentral.com/submit
() Biomed Central 